\title{
Diagnosis and pathology of stress in newborn calves
}

\author{
Nikolay Shulga ${ }^{1}$, Natalia Trush $^{2, *}$, Irina Sayapina ${ }^{3}$, and Lyudmila Bugaeva ${ }^{3}$ \\ ${ }^{1}$ Far East Zone Research Veterinary Institute Amur region, Blagoveshchensk, Russia \\ ${ }^{2}$ Far Eastern state agrarian University, Blagoveshchensk, Russia \\ ${ }^{3}$ Amur state medical Academy, Blagoveshchensk, Russia
}

\begin{abstract}
The study of stress sensitivity in newborn animals is an urgent problem. According to the type of neurohumoral activity, animals differ from each other. The body's response to the effects of stress can manifest itself in the form of adaptation or exhaustion. One of the most recognized definitions of the term "disease" is damage to the structure and function of the body under the influence of external factors during the reactive mobilization of its compensatory and adaptive mechanisms. As well as a set of non-specific changes in the body that are the result of its neurohumoral response to external stimuli that are stress. Based on the above, we set the following tasks: to develop a method for detecting stressdependent animals; to study the effect of stress on the immune system of newborn calves; to study the influence of the Central nervous system on the manifestation of regrouping stress and its correction using sedatives. Experiments to study stress sensitivity were performed on newborn calves. A method was developed for detecting stress sensitivity in newborn calves, according to the formulated formula (know-how). Animals that have u.e according to the formula below 1.35 refers to stress-resistant, and with a value above 1.35-to stress-sensitive. When studying the effect of stress on the immune system, differences in indicators were found depending on stress sensitivity.
\end{abstract}

\section{Introduction}

The Amur region has natural and climatic conditions for the development of animal husbandry. Raising healthy young animals is one of the indicators of animal husbandry efficiency. [1, 2]. To restore dairy farming in the Amur region, a program is being implemented to create highly productive herds.

The work carried out on the implementation of the developed program has led to noticeable results. Goals and objectives of the programme are to stabilise the number of cattle, growth of animals specialized in meat departments, the growth of animals specialized in meat departments. Criteria for the assessment of the effectiveness of the programme are: increase in the number of beef cattle, increase the number of purebred

\footnotetext{
${ }^{*}$ Corresponding author: Letter_box_n@mail.ru
} 
animals of a meat direction on the pedigree farms of the region, obtaining progeny in terms of 100 heads of breeding stock; productivity of young animals, etc.

The preservation of young livestock is a reserve for preserving and increasing the productive herd, increasing profitability in animal husbandry. Despite scientific research and implementation of developments in animal husbandry to reduce the impact of stress on the body of young farm animals, the consequences of stress in animals are manifested by reduced resistance and underdevelopment of calves, metabolic disorders, and as a result, a large percentage of their morbidity ( up to $100 \%$ ). $[3,4]$.

An animal's body, a single complex complex. The main effector gland in the development of stress is the adrenal gland, the cortical layer of which secretes the hormone cortisone. An auxiliary, but no less important endocrine organ in this process is the thyroid gland. The thyroid gland has a versatile effect on the body. It is known that thyroid hormones stimulate heat generation, enhance oxidative processes in the body [5]. Regulation of carbohydrate, fat, protein and water-salt metabolism is carried out through the autonomic nervous system and endocrine glands. According to the type of neurohumoral activity, animals differ from each other. The body's response to the effects of stress can manifest itself in the form of adaptation or exhaustion.

Scientific papers on the study of various issues related to the stress of farm animals are not getting smaller, which means the relevance of this issue with theoretical and practical motivation. But the mechanism that underlies stress remains poorly understood and there are few scientific papers on such issues [6].

The role of the Central nervous system and hypothalamus in the development of stress is known from scientific works. The hypothalamus is involved in regulating the function of the cardiovascular, digestive, excretory, and endocrine systems. Regulation of lifesupporting functions of the body is carried out through the autonomic nervous system and pituitary gland [7].

Modern scientific methods allow us to study stress more deeply as an adaptive response of the body. Under stress, there are pronounced disorders of life. And this state of the body becomes chronic and diseases of the immunodeficiency state of the body can occur $[8,9]$. The mechanisms of this reaction developed and were genetically fixed in the course of evolution, helping the body to survive [10]. At the cellular level, there is a permeability of cellular and subcellular membranes, a decrease in the sensitivity of lymphocytes to hormonal and nervous regulation. As a result, the function of these immunocompetent cells is disrupted, as a result, the body's immune response to infection is suppressed, and patients develop "superinfection", which makes the course of the infectious disease extremely difficult $[11,12]$.

It is known that the totality of non-specific changes in the body that are the result of its neurohumoral response to external stimuli, G. Selye called stress, and the factors that cause it - stressors. Changes in the body caused by a stressor, he called the General adaptation syndrome, which is actually a clinical manifestation of stress [13].

In the development of stress, or General adaptation syndrome, G. Selye identified three stages: 1. Stage anxiety which continues for several hours after the beginning of action of harmful factors. The changes that occur at the stage of anxiety are just that the symptoms that the scientist observed in his first experiments are hypertrophy of the adrenal cortex, atrophy of the thymus and lymph nodes, ulcers of the stomach and duodenum, weight loss. As experiments have shown, the body's resistance to the damaging factor at the stage of anxiety temporarily decreases. 2 . the stage of resistance, or adaptation. If the body does not die during the first hours of the stress factor, it adapts to it after some time, learns to exist in extreme conditions (cold, noise, pain, etc.), during this period, the resistance to the damaging factor increases. 3. the stage of exhaustion, which occurs during the prolonged action of the damaging factor. At this stage, resistance to the harmful factor decreases 
again, adaptation disappears, and changes in the body appear similar to those that occur with aging. The main postulate of the concept of G. Selye is the adaptive value of stress [14]. Stress effects of various nature (technological, temperature, rank, injuries, burns, etc.) should be considered as conditions that lead to a decrease in the level of the immune status of the body and increase the susceptibility of animals to pathogenic and potentially pathogenic microflora, constantly persisting in their body and environment $[15,16]$. This pattern manifests itself to varying degrees in farms of different forms of ownership, as stress factors that reduce the level of the immune status of the body [17].

The change in the activity of the immune system under stress depends on 3 main factors: the strength of the stressor action, i.e., the intensity of the stress reaction and its duration; the time of the stressor action relative to the phase of the immune response; the resistance of the body and/ or its immune system to stress damage [18]. In healthy animals, a moderate stress response can stimulate the activity of the immune system, enhance nonspecific anti-infectious protection, or cause a minor and rapidly passing state of reduced immunoreactivity. A long-term stress reaction is associated with the suppression of the immune response, up to the development of an immunodeficiency state $[19,20]$.

This reaction in animals develops with frequent movements to form new groups, transport, vaccination, diagnostic planned and unscheduled studies, cleaving of fangs, castration, caudoectomy, bonitirovke, change of caring staff or their daily routine, conditions of detention, etc.

With epizootic character, the development of a stress reaction and inhibition of immunoreactivity is transient, and the state of the immune system normalizes a few weeks after the stressful impact. With longer-term stress exposure, a persistent immunodeficiency condition develops, which is an important risk factor and leads to an increase in the body's susceptibility to diseases. Various combinations of the main reactions of the body constitute the essence of diseases.

The recovery of the body from the effects of stress depends on its genetic characteristics and the physiological ability of the body to adapt. The strength of the stress reaction depends on the duration and factors causing it, accompanied by changes in hormonal and vascular reactions, changes in electrolytic metabolism, and blood composition. For newborn calves and piglets, such an overstrain of the body's regulatory mechanisms can result in death. The strength of the stress reaction depends on the duration and factors causing it, accompanied by changes in hormonal and vascular reactions, changes in electrolytic metabolism, and blood composition. For newborn calves and piglets, such an overstrain of the body's regulatory mechanisms can result in death.

One of the most recognized definitions of the term "disease" is damage to the structure and function of the body under the influence of external factors during the reactive mobilization of its compensatory and adaptive mechanisms. As well as a set of non-specific changes in the body that are the result of its neurohumaral reaction to external stimuli that are stress [21]. Based on the above, we set the following tasks: to develop a method for detecting stress-dependent animals; to study the effect of stress on the immune system of newborn calves; to study the influence of the Central nervous system on the manifestation of regrouping stress and its correction using sedatives.

\section{Materials and Methods}

Experiments to study stress sensitivity were performed on newborn calves contained in individual cells.

The method of conducting experiments is as follows: heart rate and respiratory rate were measured in newborn calves before weaning. Then the animals were exposed to a sharp 
single sound signal, the sound pressure strength of 90-100 decibels (DB), after which the heart rate and respiratory rate were measured.

The data obtained from 16 calves were evaluated in conventional units, grouped into a table, and the arithmetic mean and its deviation were determined. According to the results, calves were divided into animals with increased and reduced stress sensitivity. Then a series of experiments was carried out, which consists in the following: two groups of calves were formed on the principle of analogues, 16 animals each depending on the stress sensitivity. The first group-stress-resistant calves, the second - stress-dependent. Calves of both groups were taking blood from the jugular vein, was performed hematological and biochemical tests: counting the number of red blood cells and hemoglobin, white blood cells; calculated leukocyte formula, phagocytic activity of neutrophils (FAN), serum total protein was determined with a Refractometer, and the protein fractions using electrophoresis in gel agarose according to the method Chikishev V. M., AndAlso the number of immune proteins in TCC (zinc-sulphate test) according to the method of Blinov N. I.

To study the effect of stress on the immune system, experiments were conducted on newborn calves in the number of 29 animals, whose blood was examined before and after regrouping and after 10 days, blood was taken from the jugular vein in 2 test tubes, one was pre-introduced with a stabilizer-heparin. The stabilized blood was examined for the content of red blood cells and hemoglobin, white blood cells and leukocyte formula, and the phagocytic activity of neutrophils was determined by the method of p. N. Smirnov. The total protein of refractometry, albumins and immunoglobulins were determined in the blood serum using the method of N. I. Blinov.

To study the influence of the nervous system on the manifestation of stress, a series of experiments was conducted. A series of experiments was aimed at smoothing the effect of regrouping stress on the immunity of animals and resistance to respiratory diseases of calves $(\mathrm{p}=29)$.

The essence of the experiments is as follows: calves were fed sedatives together with milk a few hours before the regrouping, control calves were not fed sedatives before the regrouping. After two weeks, blood was taken from all groups of animals and clinical studies were conducted. In addition, they were constantly monitored with the registration of all cases of animal disease, the severity of the course, the effectiveness of treatment and the outcome.

\section{Results}

As a result of an experiment to study the stress sensitivity of newborn calves, the average value of $c u=1,35$ with deviations of $\max =1.38$ and $\min =1.32$ was obtained. According to cu, newborn calves with a cu value greater than 1.38 are classified as animals with increased stress sensitivity, calves with a cu within 1.32-1.38 are classified as having an average degree of stress sensitivity, and animals with a cu value lower than 1.32 are stress resistant.

When studying the effect of stress on the immune system, differences in indicators were found depending on the stress sensitivity (table 1). According to table 1, calves with increased stress sensitivity have worse immune performance than calves with reduced stress sensitivity. There are significant differences in LAS $(p<0.001)$ and FAL $(p<0.001)$, as well as in the number of eosinophils $(\mathrm{p}<0.001)$, in the content of total protein and immunoglobulins $(\mathrm{p}<0.001)$. 
Table 1. Blood parameters of the calves, depending on the stress sensitivity $(n=16)$.

\begin{tabular}{|l|c|c|c|}
\hline \multirow{2}{*}{ Indicators } & \multirow{2}{*}{ Norm } & \multicolumn{2}{c|}{ Stress sensitivity } \\
\cline { 3 - 4 } & $50.0-67.0$ & $54.5 \pm 0.7$ & $59.6 \pm 0.9^{*}$ \\
\hline Total protein, g/ 1 & $20.0-40.0$ & $24.2 \pm 0.3$ & $26.4 \pm 0.1^{*}$ \\
\hline Immunoglobulins, g / 1 & $22.0-42.0$ & $44.4 \pm 0.3$ & $45.1 \pm 0.2$ \\
\hline \% of immunoglobulins to total protein level & $5.0-7.5$ & $5.1 \pm 0.3$ & $5.4 \pm 0.1$ \\
\hline Red blood cells x 1012/1 & 7.0 & $7.0 \pm 0.3$ & $7.4 \pm 0.1$ \\
\hline White blood cells x 109/1 & $90.0-110.0$ & $89.0 \pm 1.0$ & $90.0 \pm 0.5$ \\
\hline Hemoglobin, g / 1 & $22.0-45.0$ & $40.9 \pm 0.8$ & $41.3 \pm 0.7$ \\
\hline Neutrophils, \% & $5.0-8.0$ & $2.5 \pm 0.2$ & $6.0 \pm 0.4^{*}$ \\
\hline Eosinophils, \% & $40.0-65.0$ & $56.6 \pm 0.3$ & $53.7 \pm 0.3$ \\
\hline Lymphocytes, \% & $20.0-30.0$ & $25.3 \pm 0.2$ & $29.2 \pm 0.4 *$ \\
\hline Lysozyme activity of blood serum, \% (LAS) & $30.0-60.0$ & $45.3 \pm 0.5$ & $51.1 \pm 0.6 *$ \\
\hline $\begin{array}{l}\text { Phagocytic activity of white blood cells, \% } \\
\text { (FAL) }\end{array}$ & & & \\
\hline
\end{tabular}

* - differences are significant $\mathrm{p}<0.001$

The conducted research allows us to further form common groups of calves depending on the stress sensitivity, thereby reducing the impact of regrouping stress (technological stress) on the animal body and thus prevent the occurrence of diseases of calves.

When studying the effect of regrouping stress on the immune system of calves, it was found that the content of red blood cells in calves decreased by $14.8 \%$ after regrouping, and hemoglobin $4.2 \%$, the total number of white blood cells decreased by $21.4 \%$. Phagocytic activity of neutrophils (PHAN) decreased by $13.1 \%$.

The number of albumins indicating pathological changes in the liver is reduced by $25.0 \%$. The total number of immune proteins is also reduced by $27.3 \%$, and the ratio of immunoglobulins to total protein by $25.7 \%$. For all indicators that characterize immunity, there was a decrease after regrouping. Regrouping stress has a negative effect on the overall immune performance of calves ' blood (table 2).

Table 2. Blood Values of calves before and after regrouping $n=29, M \pm m$.

\begin{tabular}{|l|c|c|c|}
\hline \multicolumn{1}{|c|}{ Indicators } & Norm & Before regrouping & After regrouping \\
\hline Red blood cells, x1012/1 & $5.0-7.5$ & $6.2 \pm 0.2^{*}$ & $5.4 \pm 0.1$ \\
\hline Hemoglobin, g / 1 & $90-110$ & $69.8 \pm 0.6$ & $67.0 \pm 0.7$ \\
\hline White blood cells, x109/1 & $4.5-12.0$ & $5.1 \pm 0.1^{*}$ & $4.8 \pm 0.1$ \\
\hline FAN. \% & $30-60$ & $31.4 \pm 0.4^{*}$ & $29.8 \pm 0.3$ \\
\hline lymphocytes',\% & $40-65$ & $67.4 \pm 0.7$ & $65.3 \pm 0.6^{*}$ \\
\hline Eosinophils, \% & $5-8$ & $5.5 \pm 0.1$ & $6.7 \pm 0.1$ \\
\hline Monocytes, \% & $2-7$ & $2.5 \pm 0.1$ & $2.3 \pm 0.1$ \\
\hline Rod-shaped neutrophils, \% & $2-5$ & $3.5 \pm 0.1$ & $3.3 \pm 0.1$ \\
\hline $\begin{array}{l}\text { Segmentonuclear } \\
\text { neutrophils, \% }\end{array}$ & $20-35$ & $23.0 \pm 0.3^{*}$ & $20.3 \pm 0.1$ \\
\hline Total serum protein, g /1 & $50-67$ & $60.2 \pm 0.4^{*}$ & $57.5 \pm 0.3$ \\
\hline г/лAlbumins, g/1 & $20-38$ & $30.5 \pm 0.4^{*}$ & $24.4 \pm 0.4$ \\
\hline Immunoglobulins, g/1 & $20-40$ & $19.6 \pm 0.3^{*}$ & $15.4 \pm 0.3$ \\
\hline $\begin{array}{l}\text { of immunoglobulins to total } \\
\text { protein }\end{array}$ & $22-42$ & $33.7 \pm 0.3^{*}$ & $26.8 \pm 0.2$ \\
\hline
\end{tabular}

Note: $*$ - differences are significant $\mathrm{p}<0.001$

Studies have shown the effect of regrouping stress on the immune system of young animals. The effect of stress was shown on both cellular and humoral immune factors. Humoral changes are related to immune proteins, namely in reducing the amount of total protein, albumins and globulins in blood serum. The decrease in cellular immunity factors is manifested in a decrease in the total number of white blood cells, and most importantly, 
the number of neutrophils responsible for the cellular defense of the body in the form of phagocytosis decreases. The total number of lymphocytes responsible for the production of antibodies in the body also decreases. In General, our research fits into the General theory of the negative impact of stress on the immune system of animals.

This provision has been repeatedly confirmed by many studies of domestic and foreign authors. Stress factors have a negative impact on the immune system, primarily at the cellular level, which we have successfully proved. Changes in the morphological picture of blood under the influence of stress factors are reliable $(\mathrm{p}<0.001$ and are written into the General knowledge about the pathological effect of stress on the body. We found that $61.3 \%$ of animals have increased stress sensitivity.

To study the influence of the nervous system manifestation of the stress indices of total protein in blood of calves in all groups were significantly different in different groups $(p<0.001)$, the difference between control and stress sensitive group was $11.3 \%$, and stress resistant of $15.8 \%$, while the content of total protein in blood of control calves was less than the background values (table 3 ).

Table 3. Blood Values of calves after regrouping $(M \pm m),(n=29)$.

\begin{tabular}{|c|c|c|c|c|c|c|}
\hline \multirow[b]{2}{*}{ Indicators } & \multirow{2}{*}{$\begin{array}{c}\text { Backgrou } \\
\text { nd }\end{array}$} & \multirow[b]{2}{*}{ Norm } & \multicolumn{3}{|c|}{ Group } & \multirow[b]{2}{*}{ Primas\% } \\
\hline & & & control & $\begin{array}{c}\text { stress- } \\
\text { sensitive. }\end{array}$ & $\begin{array}{c}\text { stress- } \\
\text { resistant. }\end{array}$ & \\
\hline $\begin{array}{l}\text { total protein of } \\
\text { the body. } \\
\text { blood, } g / 1\end{array}$ & $60.0 \pm 0.4$ & $50.0-67.0$ & $57.5 \pm 0.4$ & $64.0 \pm 0.2 *$ & $66.6 \pm 0.3^{*}$ & $11.3-15.8$ \\
\hline $\begin{array}{l}\text { albumins, } \mathrm{g} / \mathrm{l} \\
\text { immunoglobuli } \\
\mathrm{n}\end{array}$ & $30.5 \pm 0.4$ & $20.0-38.0$ & $24.04 \pm 0.4$ & $36.5 \pm 0.3 *$ & $39.2 \pm 0.3 *$ & $49.6-60.7$ \\
\hline $\begin{array}{l}\text { immunoglobuli } \\
\mathrm{n}\end{array}$ & $19.6 \pm 0.3$ & $20.0-40.0$ & $15.4 \pm 0.3$ & $24.2 \pm 0.4^{*}$ & $26.2 \pm 0.4^{*}$ & $57.1-70.1$ \\
\hline $\begin{array}{l}\text { white blood } \\
\text { cells x } 109, \mathrm{~g} / 1\end{array}$ & $6.2 \pm 0.2$ & $5.0-7.5$ & $5.4 \pm 0.1 *$ & $6.8 \pm 0.2$ & $7.1 \pm 0.1$ & $25.9-31.5$ \\
\hline $\begin{array}{l}\text { white blood } \\
\text { cells x } 109, \mathrm{~g} / 1\end{array}$ & $6.1 \pm 0.2$ & $4.5-12.0$ & $4.8 \pm 0.1$ & $5.8 \pm 0.1 *$ & $6.5 \pm 0.1 *$ & $20.8-35.4$ \\
\hline $\begin{array}{l}\text { hemoglobin, g / } \\
1\end{array}$ & $69.8 \pm 0.6$ & $90.0-110.0$ & $67,0 \pm 0,5$ & $71.0 \pm 0.6^{*}$ & $75.6 \pm 0.7^{*}$ & $6.0-12.8$ \\
\hline lymphocytes, $\%$ & $65.3 \pm 0.6$ & $40.0-65.0$ & $67.4 \pm 0.5$ & $62.0 \pm 0.7$ & $64.2 \pm 0.6$ & \\
\hline eosinophils \% & $5.5 \pm 0.1$ & $5.0-8.0$ & $6.7 \pm 0.1 *$ & $4.7 \pm 0.1$ & $4.8 \pm 0.1$ & $28.5-$ \\
\hline monocytes, $\%$ & $2.5 \pm 0.1$ & $2,3 \pm 7.0$ & $2.3-0.1$ & $3.3 \pm 0.1$ & $2.1 \pm 0.1$ & \\
\hline $\begin{array}{l}\text { rod-shaped } \\
\text { neutrophils, \% }\end{array}$ & $3.5 \pm 0.1$ & $2.0-5.0$ & $3.3 \pm 0.1$ & $3.7 \pm 0.1$ & $2.2 \pm 0.1$ & \\
\hline $\begin{array}{l}\text { segmentonuclea } \\
\text { r neutrophi }\end{array}$ & $23.0 \pm 0.3$ & $20.0-35.0$ & $20.3 \pm 0.1$ & $26.3 \pm 0.4$ & $26.7 \pm 0.5$ & \\
\hline FAN, \% & $31.4 \pm 0.4$ & $30.0-60.0$ & $29.8 \pm 0.3$ & $32.7 \pm 0.4^{*}$ & $34.9 \pm 0.3 *$ & $9.7-17.1$ \\
\hline $\begin{array}{l}\% \text { of immune } \\
\text { proteins to total } \\
\text { protein }\end{array}$ & $33.7 \pm 0.3$ & $22.0-42.0$ & $26.8 \pm 0.2$ & $37.8 \pm 0.3^{*}$ & $39.6 \pm 0.4 *$ & $40.0-47.8$ \\
\hline
\end{tabular}

Note: * - differences are significant $\mathrm{p}<0.001$

The content of albumin in the blood serum of all groups of calves significantly differs, so the difference between the control group and the stress-sensitive group of calves was $49.6 \%$, and between the control and stress-resistant group of calves was $60.7 \%$.

Low albumin content in the blood indicates violations in the liver of animals. The content of red blood cells in calves of the control group is significantly lower by $25.9 \%$ than in calves of the stress-sensitive group and by $31.5 \%$ than in calves of the stressresistant group. There are significantly fewer white blood cells in comparison with the 
stress-sensitive group by $20.8 \%$ and in comparison with the stress-resistant group by $35.4 \%$. Hemoglobin by $6.0 \%$ and $12.8 \%$, respectively.

There are significantly more eosinophils in the blood of calves of the control group $(p<0.001)$, which may indicate possible inflammatory processes. Phagocytic activity of neutrophils (FAN) in calves of the control group significantly lower by $9.7 \%$ than that of calves stress sensitive group and $17.1 \%$ than the calves in the stress resistant group, $\%$ of immune proteins in serum of total protein in calves of the control group was significantly below $40.0 \%$, compared to calves stress sensitive group and $47.8 \%$ in comparison with calves stress resistant group.

\section{Discussion}

In almost all indicators of blood condition, calves in the control group are worse than calves in the stress-sensitive and stress-resistant groups. The use of sedatives helps to smooth out the stress of regrouping, especially if you pre-divide all animals by stress sensitivity. The role of the Central nervous system in the manifestation of stress in experiments with newborn calves was confirmed. This experiment clearly characterizes the influence of the Central nervous system on the manifestation of regrouping stress. In General, our research confirms the General theory of the negative impact of stress on the immune system of animals.

Studies have shown that stress affects both cellular and humoral immune factors. namely, in reducing the amount of total protein, albumins and globulins in the blood serum.

The number of neutrophils responsible for the cellular defense of the body in the form of phagocytosis decreases, and the total number of white blood cells decreases. The total number of lymphocytes responsible for the production of antibodies in the body decreases.It was found that stress factors have a negative impact on the immune system, primarily at the cellular level. Changes in the morphological picture of blood under the influence of stress factors are reliable $(p<0.001)$ and fit into the General knowledge about the pathological effect of stress on the body. Studies have found that $61.3 \%$ of animals have increased stress sensitivity.

Set so that the values of total protein in blood of calves in all groups were significantly different in different groups, so the difference between control and stress sensitive group was $11.3 \%$, and stress resistant of $15.8 \%$, while the content of total protein in blood of control calves was less than background values.

Thus, a method was developed for detecting stress sensitivity in newborn calves, according to the formula formulated by us (know-how). Animals that have u.e according to the formula below 1.35 refers to stress-resistant, and with a value above 1.35 -to stresssensitive.

Differences were found in the content of total protein and immunoglobulins in the blood sera of calves depending on stress sensitivity, as well as in the phagocytic activity of leukocytes and lysozyme activity of blood sera.

\section{Conclusions}

The experiment reliably indicates the effect of regrouping stress on the immune system of newborn calves. A blood test conducted after regrouping showed a significant decrease in all indicators compared to the blood parameters before the regrouping. 


\section{References}

1. A. Leorda, M. Timoshko Prevention of digestive tract dysfunction in calves under transport stress, Veterinary medicine of agricultural animals 1, 61-63 (2007)

2. 2.A. Salo, V. Popov, M. Poberukhin, Stress Tolerance of purebred and crossbred young animals to transport and pre-slaughter stress. Innovative ways to improve the efficiency of agricultural production mater. International. Science - practice. Conf. Russian Academy of agricultural Sciences, all-Russian research Institute. Institute of meat cattle breeding, pp 116-117 (2010)

3. N. M. Trush Morpho-physiological aspects of growth and adaptation, International scientific readings: collection of articles of the International scientific and practical conference) 11-14 (2020)

4. N. M. Trush On the relationship between the morphofunctional state of the thyroid and adrenal glands and the safety of calves. International scientific readings: collection of articles of the International scientific and practical conference, 32-36 (2019)

5. C. M. Avylov the Influence of stress factors on the resistance of the body of pigs . Veterinary medicine of agricultural animals 3, 46-47 (2006)

6. E. Azhmuldinov Comparative assessment of the adaptive ability of various breeds of bulls. Ways to intensify production and processing of agricultural products and current conditions. Materialy mezhdun. scientific and practical Conf. in 2 parts, 54-56 (2012)

7. I. Lyapina, E. Azhmuldinov, N. Belov Morphological and biochemical parameters of blood of young cattle under various conditions of its maintenance, News of the Oreburg state agrarian University, 136-138 (2006)

8. N. M. Zimin, Hormones and their role in metabolism, Veterinary medicine of agricultural animals 9, 4-11 (2006)

9. Y. Scherbatykh, Peter, Psychology of stress and methods of correction, 256 (2006)

10. S. N. Himicheva, L. D. Samusenko Correction of technological stress in young cattle Biology in agriculture 4 (13), $10-12$.

11. S. Batanov, O. Starostina Milk productivity of first-born cows of different stressresistance, Zootechnia 2, 18 -19 (2005)

12. E. M. Ueremey Stress state of the body and its influence on the productivity of cows in dairy complexes. Scientific notes of the educational institution "Vitebsk order" Badge of honor " state Academy of veterinary medicine 2, 143-145 (2011)

13. L. Teltsov Health and laws of individual development. Materials scientific. practical Conf. dedicated to the memory of prof 3, 344-358 (2007)

14. L. Teltsov Concept of growing highly productive animals. Materials of the international scientific and practical conference, To the 25th anniversary of the Department of animal science of the Bryansk state agricultural Academy, 21-31 (2008)

15. N. Shulga., D. Petrukhin, D. Zhelyabovskaya Some aspects of colostral immunity formation in newborn animals, Vestn. Krasgau 8, 136-139 (2012)

16. S. Dikunina, L. Plavshak, I. Shulga, N. Shulga. Technological scheme of prevention of respiratory diseases of newborn calves, 12, 198-202 (2015)

17. M. Zurabov., Z. Zurabova Some parameters of the adaptation of highly productive cows, imported to the territory of the RT from foreign countries to new conditions. Scientific notes of the Kazan state Academy of veterinary medicine Of N. E. Bauman, 211, pp 259-262 (2012) 
18. V. Levakhin, E. Azhmuldinov, M. M. Titov Growth Intensity and adaptive qualities of bulls of various breeds under the influence of technological stress factors. Bulletin of meat cattle breeding. 31(89), 54-58 (2015)

19. L. Karpenko, A. M. Enukashvili Yu. Seasonal changes in the mineral composition of blood serum of cattle. Materials of H1P mezhdunarod. Moscow veterinary Congress 201 (2005)

20. V. Lyapina Reducing losses of meat products when weaning calves from cows and subsequent stresses during the period of growing and selling bullocks Izvestiya Orenburg state agrarian University. 4, 243-246 (2013)

21. A. Konovalov. Methodology and practice of assessing the stress resistance of cattle Vestnik agro-industrial complex of the $u$ er ga region. 1, 38 -42 (2011) 